\title{
Sciendo
}

\section{THE EFFECTS OF HEAT STRESS ON THE BEHAVIOUR OF DAIRY COWS - A REVIEW*}

\author{
Piotr Herbut ${ }^{1,4}$, Gundula Hoffmann ${ }^{2}$, Sabina Angrecka ${ }^{1 \bullet}$, Dorota Godyń ${ }^{3}$, \\ Frederico Márcio Corrêa Vieira ${ }^{4}, \mathrm{Krzysztof} \mathrm{Adamczyk}^{5}$, Robert Kupczyński ${ }^{6}$ \\ ${ }^{1}$ Department of Rural Building, Faculty of Environmental Engineering and Land Surveying \\ University of Agriculture in Krakow, Kraków, Poland \\ ${ }^{2}$ Department of Engineering for Livestock Management, Leibniz Institute for Agricultural Engineering \\ and Bioeconomy, Potsdam, Germany \\ ${ }^{3}$ Department of Production Systems and Environment, National Research Institute of Animal \\ Production, 32-083 Balice n. Kraków, Poland \\ ${ }^{4}$ Grupo de Estudos em Biometeorologia - GEBIOMET (Biometeorology Study Group), \\ Federal University of Technology - Paraná (UTFPR), Dois Vizinhos, Paraná, Brazil \\ ${ }^{5}$ Department of Cattle Breeding, Faculty of Animal Sciences, University of Agriculture in Krakow, \\ Poland \\ ${ }^{6}$ Department of Animal Hygiene and Animal Welfare, University of Environmental and Life Sciences, \\ Wrocław, Poland \\ •Corresponding author: s.angrecka@ur.krakow.pl
}

\begin{abstract}
Heat stress in livestock is a function of macro- and microclimatic factors, their duration and intensity, the environments where they occur and the biological characteristics of the animal. Due to intense metabolic processes, high-producing dairy cows are highly vulnerable to the effects of heat stress. Disturbances in their thermoregulatory capability are reflected by behavioural, physiological and production changes. Expression of thermoregulatory behaviour such as reduction of activity and feed intake, searching for cooler places or disturbances in reproductive behaviours may be very important indicators of animal welfare. Especially maintenance of standing or lying position in dairy cattle may be a valuable marker of the negative environmental impact. Highly mechanized farms with large numbers of animals have the informatic system that can detect alterations automatically, while small family farms cannot afford this type of equipment. Therefore, observing and analysing behavioural changes to achieve a greater understanding of heat stress issue may be a key factor for developing the effective strategies to minimize the effects of heat stress in cattle. The aim of this review is to present the state of knowledge, over the last years, regarding behavioural changes in dairy cows (Bos taurus) exposed to heat stress conditions and discuss some herd management strategies providing mitigation of the overheat consequences.
\end{abstract}

Key words: environment, welfare, dairy cows, Bos taurus, heat stress, behaviour

*The research was financed by the Ministry of Science and Higher Education of the Republic of Poland by statutory activity. 
The interaction between the thermal environment and the body of an animal influences behaviour, physiology, reproduction and productivity (Hempel et al., 2019). When the optimal air temperature conditions are exceeded, a cow will attempt to cope with the new environmental situation. The degree of stimulation of the body systems is determined by the intensity of the heat stress (HS) response as well as the consequences that it brings to the organism. The HS response of dairy cow may vary depending on the genotype of individual breeds, stage of lactation, milk production, housing system, climate zone, altitude, bedding type, diet and cooling management strategies, and most of all on the duration and intensity of suboptimal environmental conditions (Fournel et al., 2017; Galan et al., 2018; Broucek et al., 2020; Saizi et al., 2019; Theusme et al., 2021).

Cows have physiological and behavioural mechanisms to adapt to challenges presented by the environment in which they live. High heat load in animal surroundings may induce changes in behaviour, including motor activity, frequency of lying down and time spent resting and standing, reproductive behaviour, feed and water intake, aggression, fearfulness and increased or altered vocalisation (Polsky and von Keyserlingk, 2017).

Study about the behavioural needs of cows to ensure their welfare during HS is a challenge for scientists and a practical requirement for farmers. Highly mechanized farms with large numbers of animals have individual records for each cow and the informatic system can detect alterations automatically. Small family farms cannot afford this type of equipment, but as they have less animals, farmers can be trained to observe individual changes of behaviour in order to detect heat stress and apply mitigation options. Various studies have outlined much on the coping strategies but there is still a need to relate the behavioural changes and thermal adaptability of cattle. Expanded knowledge on these topics has been increasingly commonly used in the development of remote herd monitoring devices, but also it gives a broader view of cognitive, emotional and social characteristics of farm animals, which in terms of animal welfare assumptions is essential for better understanding of their motivations and needs (Marino and Allen, 2017; Benaissa et al., 2019).

The aim of this paper is to review and systematize the current state of knowledge on the topic of behavioural changes caused by HS in dairy cows (Bos taurus). For the analysis of issues related to climate change and scientific research on the behaviour of cattle conducted in this context, the latest scientific publications in English were selected mainly from the last fifteen years. The snowball method was used to search for references, and the relevant information that had to be completed was searched by using keywords used in this article based on the Scopus browser.

\section{Environmental factors influencing heat stress}

The risk of high temperatures in relation to animal welfare is well known (Schauberger et al., 2020). Generally, for the most cow breeds fluctuations of air temperature within a range of -0.5 to $20.0^{\circ} \mathrm{C}$ and relative humidity between 60 to $80 \%$ are identified as thermo neutral values. In these ranges air parameters do 
not much induce physiological or behavioural changes among cows. However, other relevant microclimate elements, such as air movement and sunlight, also play a significant role in evoking HS responses in animals (West, 2003; Da Silva et al., 2010).

Heat from incoming solar radiation that reaches an animal in a shaded location also includes radiation from the ground, which is both emitted by heated soil and reflected (Berman, 2019). The ability of animals to deal with HS resulting from solar radiation depends on the physical characteristics of their skin and coats (Da Silva et al., 2010).

The sense of heat from solar radiation could be partly reduced by changes in air velocity, which influence the convection cooling of cattle. The effective air velocity recommended for dairy cows in the United States during periods of high ambient temperatures is from 1.8 to $2.8 \mathrm{~m} / \mathrm{s}$ (Bailey et al., 2016). However, the airflow velocities in naturally ventilated barns are very heterogeneously distributed, and turbulence occurs (Wu et al., 2012; Herbut et al., 2013). In addition, the body of a cow may disturb or scatter the stream of the airflow, e.g. a standing cow may affect the cooling airflow to any other cows standing or reclining downstream (Berman, 2019).

Over the years, attempts have been made to create an optimal method for determining the risk of heat stress, based on environment measurements of basic air parameters. Many environmental indices have been proposed, such as the temperature-humidity index (THI) (National Research Council, 1971), black globe-humidity index (BGHI) (Buffington et al., 1981) and comprehensive climate index (CCI) (Mader et al., 2010). Behavioural indicators of thermal stress can be directly measured from animals; the environmental parameters that can be considered risk factors can also be directly measured. Indicators based only on environmental parameters can be used to set thresholds, i.e., the limits beyond which the risk of animals undergoing thermal stress increases. However, animals do not necessarily react negatively when these limits are exceeded.

\section{Thermal acclimatization of cattle}

The resistance of cows to thermal environmental stress consists of their adaptation and responses to short-term environmental challenges to maintain thermal balance and general homeostasis (Vasconcelos et al., 2020 a). There are also a number of factors that determine the conditions in which the critical temperature for an individual animal can be exceeded. These factors include body surface area, heat production by the animal and losses due to evaporation. The amount of subcutaneous fat, coat thickness, density and length of the hair coat, and the precipitation and mud in an animal's hair coat are important (Chase, 2011).

Dairy cows, as homeothermic animals, are able to adapt to changing temperature and relative humidity conditions within a certain range (Kadzere et al., 2002). Depending on the growing stage, different ranges of thermoneutral temperatures are given (Figure 1). 


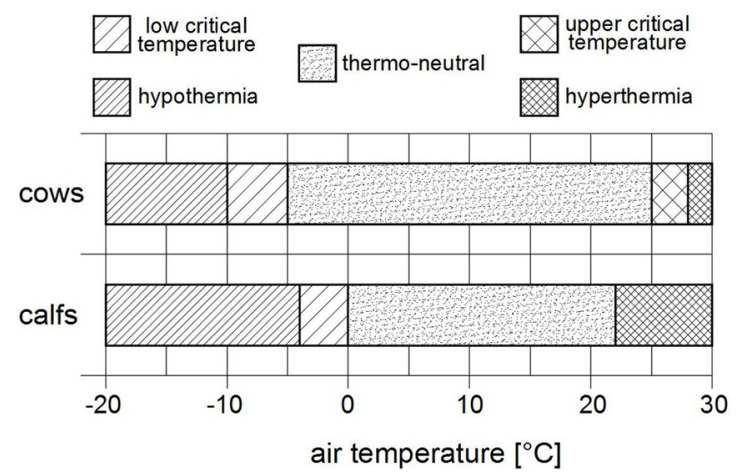

Figure 1. Thermal zones for dairy cow depend on air temperature (own study based on Manzoor et al., 2019)

During periods of excess heat in the environment of an animal, the homeostatic mechanisms of the body are activated to re-establish the thermal status of the internal environment or to regulate it to within acceptable physiological limits (Vasconcelos et al., 2020 b). Homeostatic mechanisms induce a shift in the energy metabolism to decrease metabolic heat production (Baumgard and Rhoads, 2012). Reduced feed intake is one of the reasons of negative energy balance, but instead of mobilization of fat storage, the animal body uses primarily glucose- and muscle-derived proteins as fuel (Rhoads et al., 2013). The biological oxidation of sugars and amino acids produces less heat than the oxidation of fatty acids. Generally it may be stated that HS directly (not mediated by feed intake) affects fuel selection and overall energetics (Rhoads et al., 2013). Moreover, currently the development of DNA-based methods, a high throughput approach and bioinformatics analysis may bring a better understanding of underlying biological pathways of HS and the productive performance in livestock (Srikanth et al., 2017; Liu et al., 2020). Using of these new approaches in livestock studies may lead to identification of the genes and thus to elaborating the breeding strategies of dairy cow with superior thermotolerance (Srikanth et al., 2017).

Unfavourable ambient conditions cause physiological or behavioural responses; however, it is most often a combination of both (Ratnakaran et al., 2017). The behavioural changes constitute a response to HS and aim to assist the already triggered physiological changes in maintaining homeostasis. Physiological changes are induced by increasing respiratory and heart rates, followed by milk efficiency and finally reproduction. The duration of the HS and individual ability of each cow to acclimatize influences the magnitude and intensity of this reaction (Heinicke et al., 2018; Saizi et al., 2019). Due to the positive relationship between milk yield and heat production, higher-yielding cows are more affected by thermal stress than loweryielding animals. It is an effect that higher yielding cows have higher metabolic energy and therefore higher risks of suffering from heat stress at lower thresholds. However, the extent to which milk production is affected also depends on traits and parities, e.g., multiparous cows are more susceptible to HS than primiparous cows (Kadzere et al., 2002; Bernabucci et al., 2014). 


\section{Behavioural differences between housing systems}

The quality of cow living environments depends on the farm management. Therefore, it is important for farmers to be able to implement appropriate measures to limit and abate harmful stressors. Pasture access has benefits for dairy cow behaviour, in terms of grazing, improved lying/resting times and lower levels of aggression (Arnott et al., 2017). In a freestall barn, a cow spends 12-14 h/d lying down, 3-5 h/d feeding, 2.5-3.5 h/d outside the pen, 2-3 h/d socializing, and $30 \mathrm{~min} / \mathrm{d}$ drinking (Gomez and Cook, 2010). However, a cow's time budget can vary depending on the environment and management system (Smid et al., 2020). Cows on pasture will lie down (also ruminate) for between 8.3 and $9.8 \mathrm{~h} / \mathrm{d}$ and graze for between 8.3 and $9.0 \mathrm{~h} / \mathrm{d}$ (Tucker et al., 2008). Furthermore, in tie stalls, the lying time ranges from 9.7 to $11.3 \mathrm{~h} / \mathrm{d}$, and cows spend 3.8 to $4.6 \mathrm{~h} / \mathrm{d}$ eating (Norring et al., 2008). Dairy cows sleep $3-4 \mathrm{~h}$ in short $3-5 \mathrm{~min}$ bouts throughout the day, which is only a quarter of the time spent lying down (Ternman et al., 2012). Thus, all factors that reduce the cows' optimal lying time could result in negative welfare implications.

Depending on the level of heat stress, behavioural coping strategies in cows usually involve changes in motor activity, preferential occupation of the barn or shaded pasture areas, feeding or social behaviours (Schutz et al., 2010; Charlton and Rutter, 2017). Based on the results of research and observations published in the references collected for this article, a Table 1 of behavioural changes in cattle occurring with HS was created. In legend of the table associations with each behavioural changes were classified at three levels: slight, moderate or strong. Also, level "dependent on milk yield of cows" was created, which means changing in association with cow's lactation cycle.

Table 1. Behavioural changes in cattle occurring with heat stress (own elaboration based on Kadzere et al., 2002; Munksgaard et al., 2005; Cardot et al., 2008; Schutz et al., 2010; Coimbra et al., 2012; Falk et al., 2012; Karimi et al., 2015; Arnott et al., 2017; Charlton and Rutter, 2017; Ratnakaran et al., 2017; Galan et al., 2018; Kamal et al., 2018)

\begin{tabular}{l|c|c}
\hline \multicolumn{1}{c}{ Behaviour parameters } & \multicolumn{2}{c}{ Association } \\
\cline { 2 - 3 } & increase & decrease \\
\hline Feed intake & & +++ \\
Dry matter intake & $+*$ & ++ \\
Feeding time & +++ & +++ \\
Time spent drinking & $+*$ & + \\
Drinking events & + & ++ \\
Lying time & +++ & \\
Lying bouts & & \\
Time spent standing & + & \\
Locomotion & + & \\
Aggressive interactions & ++ & \\
Vocalisation & ++ & \\
Shade seeking & + & \\
Seeking areas with optimal ventilation & + & \\
\hline
\end{tabular}

slight $[+]$, moderate $[++]$, or strong $[+++]$ association;

$+*$ - Dependent on milk yield of cows. 


\section{Feeding behaviour and water intake}

Studies on feeding and drinking behaviour in cattle during HS have been conducted in different climate regions (Cardot et al., 2008; Pereyra et al., 2010; Hanušovský et al., 2017). The reduction in feed intake among heat-stressed animals is well documented by Kadzere et al. (2002), Rhoads et al. (2013), and Hill and Wall (2017). According to Baumgard and Rhoads (2012), reduced feed intake is a response that induces a decrease in the metabolic rate and is usually reported to occur within two days of the onset of HS (West et al., 2003). Changes in dry matter intake (DMI), eating and ruminating time were noted most frequently in scientific research. West et al. (2003) found a decrease in daily DMI at a level of $0.51 \mathrm{~kg}$ for every 1 unit increase in THI between the THI values of 73 and 82. Diminished feed intake is usually accompanied by reduced meal duration (Eslamizad et al., 2015). Kadzere et al. (2002) stated that high-producing cows, which are more vulnerable to heat stress, showed a greater reduction in feed intake. However, the eight-year experiment of Hill and Wall (2017) on two groups of Holstein Friesian cows, which were divided into individuals for milk traits and average individuals, did not confirm that. Moreover, the frequency of feed intake per $24 \mathrm{~h}$ increased in high-producing cows and decreased in low-yielding cows (Karimi et al., 2015). Hill and Wall (2017) observed a decline in DMI at the level of $3.8 \%$ in cows and $4.4 \%$ for average individuals when the ambient conditions changed from a mean daily THI of 68.8-73.5. However, these authors confirmed that especially the efficiency of converting DMI to milk increased. Feed efficiency increases with mild HS but rapidly decreases when HS becomes more severe (Baumgard and Rhoads, 2012; Hill and Wall, 2017). The DMI reduction was usually smaller after three weeks of hot weather, which suggests that the cows were able to acclimatize.

The latest studies indicated that thermal conditions during a dry period were also of high significance (Fabris et al., 2019). HS decreased DMI (by $0.7 \mathrm{~kg} / \mathrm{d}$ ), but this factor did not differ among treatments during the late dry period. Cows that are exposed to HS at any time during the dry period had reduced milk, protein and lactose yields in the subsequent lactation (Fabris et al., 2019). Cooling at the beginning of the dry period can increase milk efficiency, while cooling during the entire dry period resulted in an increase in milk production of $7.5 \mathrm{~kg} / \mathrm{d}$ in the subsequent lactation relative to cows that were not cooled (Dahl et al., 2017).

Based on behavioural monitoring data, it may also be stated that during the hot periods, in addition to changes in feed intake water uptake also increases (Kadzere et al., 2002; Schutz et al., 2010). Generally, it may be stated that the need for fresh water for animals kept under high ambient temperatures is extreme, as these conditions induce evaporative heat loss processes (National Research Council, 2001). Cutaneous and respiratory evaporation, faeces, and urine are key routes of water loss. In heat-stressed cattle, behavioural observations showed an increase in panting, salivation and excessive sweating rate; however, the frequency of defecation and urination was often reduced (Ratnakaran et al., 2017).

For cows producing $41.5 \mathrm{~kg}$ of milk daily in thermo-neutral conditions, the water intake is approximately $135 \mathrm{~kg}$ /day (Kadzere et al., 2002). As shown in Figure 2, variations in water intake are closely related to DMI, milk yield and air temperature 
(Cardot et al., 2008). Water for dairy cow must be provided in the right quantity because a $10 \%$ decrease in the water in a cow's body may adversely affect milk production (Pereyra et al., 2010). According to West (2003), water intake increased by a $1.2 \mathrm{~kg} /{ }^{\circ} \mathrm{C}$ increase in minimum ambient temperature. During heat stress, the cows drank water more often but in smaller amounts; thus, the total time of water intake increased (Cook et al., 2007). The proximity of the water source was more significant if no shade or sprinklers were available to alleviate the heat load (Vizzotto et al., 2013).

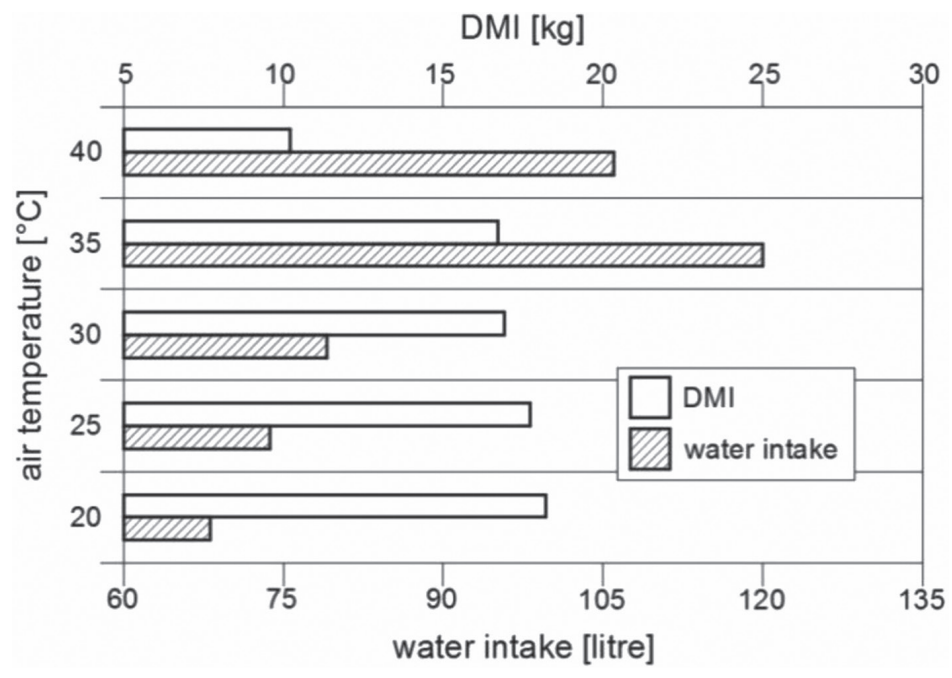

Figure 2. Changes in water intake and dry matter intake [DMI] with increasing air temperature (own elaboration based on Cardot et al., 2008)

Pereyra et al. (2010) found that the highest mean percentage of drinking bouts in Holando-Argentino cows occurred when the THI values were within the range of 74.91 to 83.95. Hanušovský et al. (2017) used continuous ruminal monitoring boluses in Holstein cows to evaluate, among other factors, the drinking regime during 24 weeks of lactation in relation to the outside temperature. During this study, the average daily air temperature was $19.03 \pm 5.19^{\circ} \mathrm{C}$, and the average number of drinking events was $9.25 \pm 1.85$. The authors established a weak linear relationship between the average daily outside temperature and the number of drinking events. During lactation weeks with higher outside temperatures, the number of drinking events among the cows also increased.

\section{Lying and standing as main examples of changes in physical activity}

Another behavioural answer of cows on HS that can be used as an indicator of the physiological state and general health is the degree of physical activity (Gaworski and Rocha, 2016; Pilatti and Vieira, 2017). During episodes of heat stress, cows are 
lethargic; they limit the amount of time spent lying down, and freestall-housed cows lie more often in manure alleys than in cubicles (Herbut and Angrecka, 2018). Daily lying time of cows in cubicles was shorter in high levels of HS but in the manure alleys this relation was reverse. Cows wanting to cool down prefer lying down on concrete and wet floors than in straw cubicles (Figure 3).

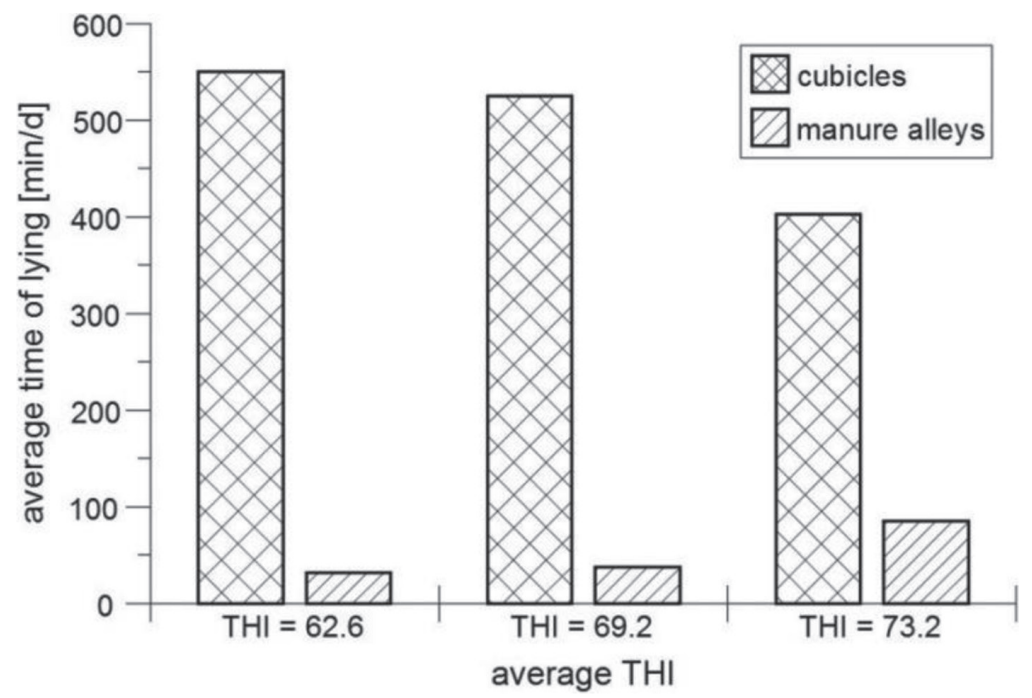

Figure 3. Daily lying time of cows in cubicles and manure alleys in relation to different levels of heat stress (Herbut and Angrecka, 2018)

As has been shown in studies, the lying position is one of the main welfare indicators (Vasseur et al., 2012). The lying position helps to control hoof disease and lameness and increases the intake of feed and rumination (Munksgaard et al., 2005). As reported by Allen et al. (2015), the duration of one resting bout under thermoneutral conditions averaged approx. 70 min. Generally, cows lay down mostly during the night due to lower air temperature values (or THI $<72$ ), which alleviate the effects of HS experienced during the daytime.

It is worth mentioning that regardless of the climatic conditions, the comfort of lying cows, including getting up and lying down, depends on, inter alia, the size and the type of the cubicles, the type of partitions between the cubicles and the number of cubicles in relation to the number of animals (Fregonesi et al., 2007). Time spent by cows in a lying position may also be affected by the social relationships in the flock, the use of resting space and their nutrition (Camiloti et al., 2012).

Key factors influencing resting behaviour, especially during heat waves, also include bedding quality, which determines the comfort of lying, including thermal comfort. Cows prefer soft bedding lined with dry material of sufficient quality that it is safe when they get up (Borshch et al., 2019), and they will adapt their lying behaviour based on previous experience (Norring et al., 2008). Research conducted 
by Fregonesi et al. (2007) showed that cow lying down time after a change from wet to dry bedding material, could increase by up to $5 \mathrm{hrs}$. Equally important was the temperature of the bedding material, which is dependent on the air temperature, the type of the material itself and its depth (Meng et al., 2015).

Cook et al. (2007) showed that different types of physical activity changed with increasing THI and that the lying time was most affected, being reduced by $3 \mathrm{hrs}$ (Figure 4). According to de Palo et al. (2006), cattle react to an increase in heat stress, represented in THI levels, by spending more time standing, which is negative for cows because it hinders proper blood circulation in their udders. This behaviour has also been explained by the fact that while standing, the cow has a larger body surface area available for heat exchange by convection and may lose more heat in this position than during lying (Herbut and Angrecka, 2018). Moreover, the study results showed that the time spent standing did not increase linearly with THI but peaked in the THI range from $80-89$. It might be caused by fatigue resulting from cumulative standing time and animal weariness, which can be independent of HS increase (Allen et al., 2015).

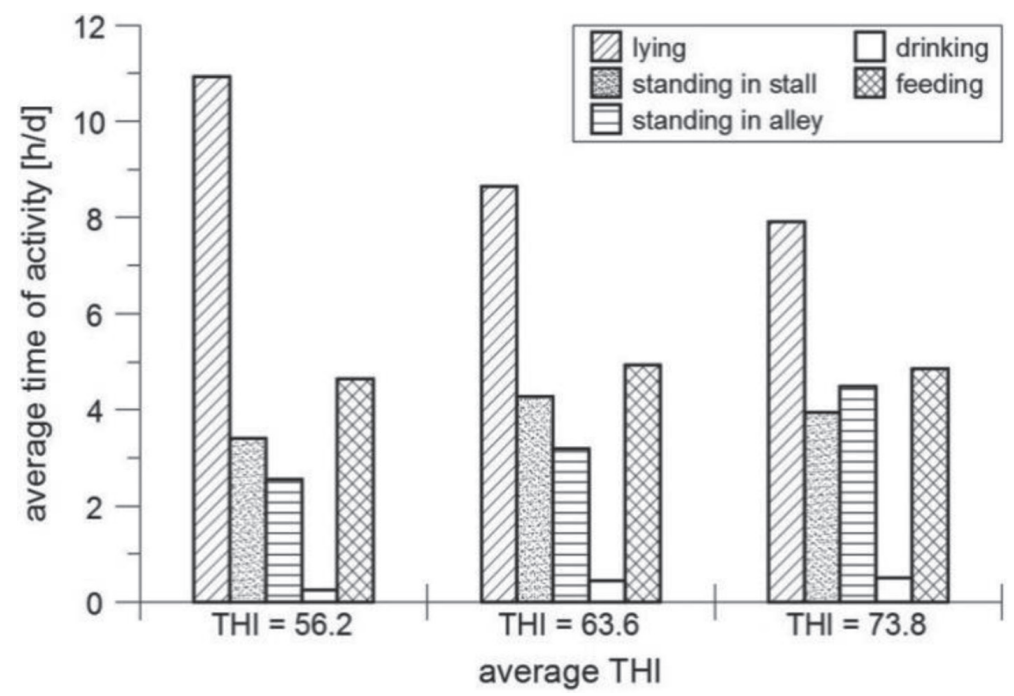

Figure 4. Change in average time of cows' activities at different levels of heat stress (own elaboration based on Cook et al., 2007)

On hot days, cows reduce contact with other individuals and alter their individual behavioural patterns. As it was mentioned before, they lie more often in a manure corridors, and this situation may lead to increase (Herbut and Angrecka, 2018). However, if the concrete of corridor is wet, this behaviour can be explained by the animal's urge to cool its body (heat exchange via conduction), which may be the case particularly when dominant cows exhibit such behaviour. Nevertheless, it should be stressed that this ambiguous behaviour observation should be studied more due to the potential heat stress mitigator (Ortiz et al., 2015). 


\section{Vocalisation}

Generally cow's vocalisations are forms of short- and long-distance communication between the herd members (Green et al., 2018). Vocalisation assessments in behavioural studies are a source of important information about the physiology and welfare state as there is a clear relationship between vocalisation and specific types of behaviour. The frequency of sounds uttered by cows significantly differs depending on whether the cow is resting, lying or exposed to a stress-inducing situation (Meen et al., 2015). Individual calls can be provoked by painful management or therapeutic procedures, weaning, nutritional needs or physiological conditions, e.g., reproductive behaviours or socialization. Currently there have been developed new technologies for automatic detection of animal sounds (Bishop et al., 2019). This kind of equipment was used to analyse cow's vocalisation regarding oestrus detection (Röttgen et al., 2020). In laying hens thermal comfort was evaluated using a real time sound-based monitoring method (Du et al., 2020). In piglets Ferrari et al. (2013) showed that an increase in air temperature increased the number of vocalisations and elevated the frequency and length of sounds. It was also found that HS significantly augmented sound intensity $(\mathrm{dB})$ and pitch $(\mathrm{Hz})$ in pigs compared with moderate temperatures or cold stress (Cordeiro et al., 2018). Moreover, turkeys responded to HS within 30 min by producing more (43\%) vocalisations (Liu et al., 2018).

In cattle, heat stress-specific vocalisation has not been studied yet. However Polsky and von Keyserlingk (2017) claimed that cows exposed to thermal stress are characterised with DMI reduction and increased ghrelin secretion, which may lead to discomfort and feeling of hunger. This may influence the vocal response (Tucker et al., 2009).

\section{Access to pasture and paddocks and the behaviour of cows}

It is well known that the access of dairy cows to pastures is important, and cows prefer to use these areas, especially at night, thereby avoiding higher THI values occurring during the daytime (Falk et al., 2012). However especially in temperate climates the THI value will often be lower at pasture than indoors. And in addition, often also TMR provision indoors causes the daytime preference for housing (Charlton and Rutter, 2017).

Cows can use shade structures or barns for protection from harsh atmospheric conditions, such as high air temperatures, rain or direct solar radiation (Van Iaer et al., 2014). This was confirmed by Oliveira et al. (2014), who showed that the heat solar radiation intensity that induced lactating Holstein (producing $12 \mathrm{~kg} / \mathrm{d}$ ) cows to stop grazing and seek shade was in the 500 to $700 \mathrm{~W} / \mathrm{m}$ range at a mean air temperature of $33.3^{\circ} \mathrm{C}$. In a New Zealand study, Fischer et al. (2008) noted that the animals began to use shade when the air temperature rose to $25^{\circ} \mathrm{C}$. Karki and Goodman (2010) also observed that cows kept in a silvopastoral system spent more time grazing due to comfortable conditions, chiefly during the afternoon period. It is also important that a low cow density in the shaded area reduces the thermal radiation emitted from the bodies of the neighbouring cows, and the heat exchange of resting cows is improved by increasing air velocity in a shaded resting area (Calegari et al., 2012). 
As demonstrated in a study by Smid et al. (2019) in which cows were allowed a free choice between the barn and paddock during the summer, cows spent more time in the paddock at night (between 20 and $06 \mathrm{hrs}$ ) than during the daytime (between 06 and $20 \mathrm{hrs}$ ). This finding was also confirmed by the studies of Legrand et al. (2009), who found that on rainy days in the summer, cows spent more time in paddocks or pastures due to the cooling effect of precipitation and to reduced solar radiation. Similar behaviour was observed in sunlit cubicles, which cows were reluctant to occupy during the daytime (Angrecka and Herbut, 2017). Other important reasons why lying times differ between pasture and indoors include, e.g. disease prevalence, competition for cubicles indoors, and more comfortable surface outside. Hence, some studies have found longer lying times at pasture (Charlton et al., 2011).

It is obvious that the activity of cows on pasture differs from their behaviour in barns. Access to water and feed on pasture may require longer walks, so they may spend less time lying than cows in barns (de Palo et al., 2006). Coimbra et al. (2012) observed that cows with access to a water trough inside a paddock spent more time drinking and drank a larger amount of water. In addition, they observed that when the water trough was located more distantly, the time spent drinking was greater for the dominant cows. Kamal et al. (2016), studying different roof materials for shading, reported that cows under asbestos with canvas roofing and trees spent more time near water troughs. These results suggest that the roof material modified the microclimate of the shaded area and that the animals compensated for the high temperatures by spending more time on water intake. The groups of trees in the pasture gave similar results (Deniz et al., 2019; Vieira et al., 2020).

Green fodder consumption is also different in grazing animals. In addition, the grass on pasture facilitates the transition from lying to standing, so the time spent standing may be prolonged. The shorter lying time is a reaction to high temperatures but carries a greater risk of lameness, especially at the subclinical stage (Allen et al., 2015). Lameness changes natural behaviour and a preference for standing and influences the choice of the place for lying down. Navarro et al. (2013), through research involving dairy cows that were housed inside and on pasture, found that there were 1.4 more lying bouts per day for housed cows than for cows on pasture, but lame cattle in both systems had similar numbers of lying bouts per day.

\section{Management strategies for heat stress reduction in dairy cows}

In nature, many animal species can look for a more favourable environment when ambient temperatures exceed their preferred thresholds. However, farmed animals have a limited opportunity to moving in search of optimal environmental conditions, especially in tie stall systems. Due to rise of global air temperatures, cows are more often exposed to temperatures to which the species is not adapted. Long heat waves impact on the well-being deterioration and decrease of productivity of dairy cows strongly. This phenomenon is really visible in reports from the European Union or the Food and Agriculture Organization (FAO) of the United Nations, which give data about large milk production losses in recent years. Management strategies for cows (in different breeds and ages) and protection against HS can be summed up by the following components: physically modifying the environment, genetic development 
of heat-tolerant breeds, and better nutritional management practices (Johnson, 2018). However, these strategies require individual assessment of animal vulnerability to HS and appropriate modification of the abovementioned components.

A number of feeding strategies are known that may provide an appropriate means of mitigating heat stress. The most important include appropriate supplementation of dietary fat, minerals, trace elements and vitamins, fibre, microbial ingredients (mostly yeast), plant extracts and other additives which have a potential to improve antioxidant and immune function (Min et al., 2019; Shan et al., 2020). In the future, probiotic supplements for feed rations should be developed. In addition, during heat stress, it is necessary to increase the supply of bicarbonate, potassium, vitamins $\mathrm{C}$ and $\mathrm{B}_{3}$ in the feed rations (Kadzere et al., 2002).

To enable cows to raise their water intake, the size and location of the water troughs should be taken into account as well as the temperature of the water which is related to the capacity of water to decrease inner cow temperature. The water intake points largely affect the behaviour associated with drinking during periods of HS (Saizi et al., 2019).

As mentioned previously, behavioural strategies of HS reduction involve looking for cooler places, including shade (Schutz et al., 2010). Increasingly, various methods of increasing shade coverage have been mentioned, including tree cover, roofs, eave extensions and the installation of sunlight-reducing mesh. Moreover, the use of shading could reduce the thermal load of cattle by $30 \%$. The impact of clouds occurring during the observations, included in the studies, contributed to the reduction in temperature of the surfaces of the stalls. During hot weather, short, ten-minute appearances of clouds caused decreases in the temperature of the stall surface of approx. $2.5^{\circ} \mathrm{C}$. On this basis, it can be concluded that the use of shading in the barn environment in the afternoon could limit the heating of cubicles (Angrecka et al., 2017).

Other methods used in barn systems include fans, tube ventilation systems, misting and air-mixing devices, as well as water droplets from low-pressure sprinkler systems in combination with fans (Kamal et al., 2018; Pinto et al., 2019) or cooling the inlet air, e.g. cooling pads, earth-air-heat exchanger (Schauberger et al., 2020). However, it should be noted that although cows under HS prefer to spend more time under sprinklers, they avoid exposing their heads to water (Chen et al., 2016). Sprinklers are most often installed in feeding alleys and resting zones so that the cows feel comfortable and do not reduce feed intake (Kadzere et al., 2002; West, 2003; Pilatti et al., 2019). This creates milder microclimates for cows due to the reduction in solar radiation exposure and a decrease in the ambient temperature (Van Iaer et al., 2014; Herbut et al., 2013; Angrecka et al., 2017). Domingos et al. (2013) showed that cows that submitted to water sprinkling and were protected against shortwave radiation in an equatorial semi-arid region had reduced values in physiological variables, i.e. rectal temperature, hair coat surface temperature and respiratory rate. In holding pens for housed cows in a tropical region, Silva and Passini (2018) compared the following: holding pen environments, the external environment, polypropylene shading, water sprinkling and combinations thereof. The same authors observed that the combination of shading, water sprinkling, and ventilation reduced values in air temperature as well as increased milk production. 
Proper management of the flock during HS conditions also includes the estimation of the range of solar radiation inside the barn. This evaluation may contribute to better protection of high-producing cows by placing them under the most beneficial thermal conditions inside the barn (Angrecka and Herbut, 2017; Angrecka et al., 2017).

\section{Conclusions}

Given the progress of global warming and constantly increasing milk yield of dairy cows, the problem of HS is currently one of the most important in livestock farming. It is also a challenge for the future in relation to concerns about sustainable development and food safety.

The most often used behavioural parameters of HS include the choice of a place for lying, time spent lying and standing, intensity of motor activity, ruminating and drinking rate. A greater preference for the standing position is one of more important - and at the same time easiest to grasp - behavioural changes related to HS. Such parameters have the advantage that they can be used for assessment of the welfare of both the whole herd and an individual animal. In addition, duration and intensity of stress should also be taken into account to estimate the potential time for cow acclimation. More research is required to identify improved comprehensive measurements of cow's welfare that can indicate real-time responses to elevated ambient temperatures and that could be incorporated into heat abatement management decisions. This can be achieved in the future by using information about cow behaviour in herd data and information about environmental conditions.

Further studies are also required to explain the relationship between cows reactions to HS and vocalization. Linking specific vocalisations with behaviour can suggest solutions for both individual animals and the herd when the welfare of the cows deteriorates.

\section{References}

A 11 e n J.D., Hall L.W., C olli e r R.J., S m ith J.F. (2015). Effect of core body temperature, time of day, and climate conditions on behavioral patterns of lactating dairy cows experiencing mild to moderate heat stress. J. Dairy Sci., 98: 118-127.

A n g r e c k a S., H e r b u t P. (2017). Eligibility of lying boxes at different THI levels in a freestall barn. Ann. Anim. Sci., 17: 257-269.

Angrecka S., Herbut P., N a w a lany G., S ok oł ow ski P. (2017). The impact of localization and barn type on insolation of sidewall stalls during summer. J. Ecol. Eng., 18: 60-66.

Arnott G., Ferris C., O ' Connell N. (2017). Review: Welfare of dairy cows in continuously housed and pasture-based production systems. Animal, 11: 261-273.

B a il e y T., S heets J., M c Clary D., S m ith S., B ridge s A. (2016). Heat Abatement. Elanco.

B a u m gard L.H., Rhoads R.P. (2012). Ruminant production and metabolic responses to heat stress. J. Anim. Sci., 90: 1855-1865.

B en a is s a S., Tuytten s.A.M., P lets D., Cattrysse H., Martens L., Vandaele L., Jos e p h W., S o n c k B. (2019). Classification of ingestive-related cow behaviours using RumiWatch halter and neck-mounted accelerometers. Appl. Anim. Behav. Sci., 211: 9-16.

B e r m a n A. (2019). An overview of heat stress relief with global warming in perspective. Int. J. Biometeorol., 63: 493-498. 
Bernabucci U., Biffani S., Buggiotti L., Vitali A., Lacetera N., Nardone A. (2014). The effects of heat stress in Italian Holstein dairy cattle. J. Dairy Sci., 97: 471-486.

B is hop J.C., Falzon G., Trotter M., Kwan P., Me ek P.D. (2019). Livestock vocalisation classification in farm soundscapes. Comput. Electron. Agric., 162: 531-542.

B or s h ch A.A., R u b a n S., B or sh ch A.V., B a b en k o O. (2019). Effect of three bedding materials on the microclimate conditions, cows behavior and milk yield. Pol. J. Natur. Sci., 34: 19-31.

Broucek J., Ryba S., Dianova M., Uhrincat M., Soch M., Sistkova M., Mala G., N ova k P. (2020). Effect of evaporative cooling and altitude on dairy cows milk efficiency in lowlands. Int. J. Biometerol., 64: 433-444.

Buffington D.E., Collazo-A rocho A., Canton G.H., P itt D., Thatcher W.W., Coll i e r R.J. (1981). Black globe-humidity index (BGHI) as comfort equation for dairy cows. Trans ASAE., 24: 711-714.

C a le gari F., C a la mari L., Frazzi E. (2012). Misting and fan cooling of the rest area in a dairy barn. Int. J. Biometeorol., 56: 287-295.

Camiloti T.V., Fregonesi J.A., von Keyserlingk M.A.G., We ary D.M. (2012). Short communication: Effects of bedding quality on the lying behavior of dairy calves. J. Dairy Sci., 95: 3380-3383.

C a rd ot V., L e R o u x Y., J u rjan z S. (2008). Drinking behavior of lactating dairy cows and prediction of their water intake. J. Dairy Sci., 91: 2257-2264.

$\mathrm{C}$ h a r $1 \mathrm{t}$ o n G.L., R u t t e r M.S. (2017). The behaviour of housed dairy cattle with and without pasture access: A review. Appl. Anim. Behav. Sci., 192: 2-9.

Char lton G.L., Rutt e r M.S., E a s t M., S in c l a i r L.A. (2011). Effects of providing total mixed rations indoors and on pasture on the behavior of lactating dairy cattle and their preference to be indoors or on pasture. J. Dairy Sci., 94: 3875-3884.

$\mathrm{C}$ h a s e L.E. (2011). Stress in dairy animals - cold stress: Effects on nutritional requirements, health and performance. Encyclopedia of Dairy Sciences, Elsevier, Amsterdam, the Netherlands, pp. 550-554.

Chen J.M., S chutz K.E., Tu cker C.B. (2016). Cooling cows efficiently with water spray: Behavioral, physiological, and production responses to sprinklers at the feed bunk. J. Dairy Sci., 99: 4607-4618.

Coimbra P.A.D., Machado Filho L.C.P., Hötzel M.J. (2012). Effects of social dominance, water trough location and shade availability on drinking behaviour of cows on pasture. Appl. Anim. Behav. Sci., 139: 175-182.

C o o k N.B., M e n t in k R.L., B en net t T.B., B u rgi K. (2007). The effect of heat stress and lameness on time budgets of lactating dairy cows. J. Dairy Sci., 90: 1674-1682.

Cordeiro A.F.D.S., Nääs I.D.A., da Silva Leitão F., de Almeida A.C., de Mour a D.J. (2018). Use of vocalisation to identify sex, age, and distress in pig production. Biosys. Eng., 173: 57-63.

D a hl G.E., Ta o S., L a p ort a J. (2017). Late gestation heat stress of dairy cattle programs dam and daughter milk production. J. Anim. Sci., 95: 5701-5710.

D a Silva R.G., Guilh er mino M.M., Mor a is D.A.E.F. (2010). Thermal radiation absorbed by dairy cows in pasture. Int. J. Biometeorol., 54: 5-11.

Deniz M., S chmitt Filho A.L., Farley J., de Quadros S.F., Hötzel M.J. (2019). High biodiversity silvopastoral system as an alternative to improve the thermal environment in the dairy farms. Int. J. Biometeorol., 63: 83-92.

De Palo P., Tate o A., Zezza F., Corrente M., Centoduc ati P. (2006). Influence of freestall flooring on comfort and hygiene of dairy cows during warm climatic conditions. J. Dairy Sci., 89: $4583-4595$.

D o m ing o s H.G.T., Ma i a A.S.C., S o u za Jr. J.B.F., Silva R.B., Vi e ir a F.M.C., Silva R.G. (2013). Effect of shade and water sprinkling on physiological responses and milk yields of Holstein cows in a semi-arid region. Livest. Sci., 154: 169-174.

Du X., Carpentier L., Teng G., Li u M., Wang C., Norton T. (2020). Assessment of laying hens' thermal comfort using sound technology. Sensors, 20: 473.

Es l a miza d M., L a m p O., D erno M., Kuhla B. (2015). The control of short-term feed intake by metabolic oxidation in late-pregnant and early lactating dairy cows exposed to high ambient temperatures. Physiol. Behav., 145: 64-70. 
Fabris T.F., Laporta J., Skibiel A.L., Corra F.N., Senn B.D., Wohlgemuth S.E., Dahl G.E. (2019). Effect of heat stress during early, late, and entire dry period on dairy cattle. J. Dairy Sci., 102: 5647-5656.

F a lk A.C., Weary D.M., Winckle r C., von Keys erlingk M.A.G. (2012). Preference for pasture versus freestall housing by dairy cattle when stall availability indoors is reduced. J. Dairy Sci., 95: 6409-6415.

F errari S., C o s t a A., Gu ari n o M. (2013). Heat stress assessment by swine related vocalizations. Livest. Sci., 151: 29-34.

F is cher A.D., R oberts N., B lu et t S.J., Verkerk G.A., M a t th ew s L.R. (2008). Effects of shade provision on the behaviour, body temperature and milk production of grazing dairy cows during a New Zealand summer. N Z J. Agricult. Res., 51: 99-105.

Fournel S., Ouellet V., Charbonn ea É. (2017). Practices for alleviating heat stress of dairy cows in humid continental climates: a literature review. Animals, 7: 37.

Fregonesi J.A., Ve ir a D.M., v on Keys erlingk M.A.G., We ary D.M. (2007). Effects of bedding quality on lying behavior of dairy cows. J. Dairy Sci., 90: 5468-5472.

Galan E., Ll on ch P., Villagra A., Le vit H., P in to S., del Prado A. (2018). A systematic review of non-productivity-related animal-based indicators of heat stress resilience in dairy cattle. PLoS One, 13 (11).

Gaw orski M., R o cha A.G.F. (2016). Effect of management practices on time spent by cows in waiting area before milking. In: Engineering for Rural Development, Malinovska L., Osadcuks V. (eds). Latvia Univ. Agriculture, pp. 1300-1304.

G o m e z A., C o o k N.B. (2010). Time budgets of lactating dairy cattle in commercial freestall herds. J. Dairy Sci., 93: 5772-5781.

Green A.C., Johnston I.N., C la rk C.E.F. (2018). Invited review: The evolution of cattle bioacoustics and application for advanced dairy systems. Animal, 12: 1250-1259.

H a nu š ov s ký O., B ír o D., Š i m k o M., Gáli k B., J u ráč e k M., R ol in e c M., He r k el’ R. (2017). Drinking regime evaluation with continuous ruminal monitoring boluses. Actafytotechn. Zootechn., 20: 1-5.

He in i cke J., H offm an n G., A m mon C., A mon B., A mon T. (2018). Effects of the daily heat load duration exceeding determined heat load thresholds on activity traits of lactating dairy cows. J. Therm. Biol., 77: 67-74.

H e m pel S., M e n z C.,P in to S., G a l a n E.,J a n k e D.,E s tellés F., Mü s c hner - S i e men s T., Wang X., Heinicke J., Zhang G., Amon B., del Prado A., Amon T. (2019). Heat stress risk in European dairy cattle husbandry under different climate change scenarios - uncertainties and potential impacts. Earth Syst. Dynam. Discuss., 10: 859-884.

Herbut P., A n g re c k a S. (2018). The effect of heat stress on time spent lying by cows in a housing system. Ann. Anim. Sci., 18: 825-833.

H e r b u t P., A n g r e c k a S., N a w a l a n y G. (2013). Influence of wind on air movement in a free stall barn during the summer period. Ann. Anim. Sci., 13: 109-119.

H i 11 D.L., Wa 11 E. (2017). Weather influences feed intake and feed efficiency in a temperate climate. J. Dairy Sci., 100: 2240-2257.

John s on J.S. (2018). Heat stress: Impact on livestock well-being and productivity and mitigation strategies to alleviate the negative effects. Anim. Prod. Sci., 58:1404-1413.

Kadzere C.T., Murphy M.R., Silanikove N., Maltz E. (2002). Heat stress in lactating dairy cows: a review. Livest. Prod. Sci., 77: 59-91.

Ka ma 1 R., Dutt T., Patel M., Dey A., Chandran P.C., Bharti P.K., B arari S.K. (2016). Behavioural, biochemical and hormonal responses of heat-stressed crossbred calves to different shade materials. J. Appl. Anim. Res., 44: 347-354.

K a mal R., D utt T., P a t e 1 M., D e y A., B hart i P.K., Chand ran P.C. (2018). Heat stress and effect of shade materials on hormonal and behaviour response of dairy cattle: a review. Trop. Anim. Health Prod., 50: 701-706.

Karimi M.T., Ghorbani G.R., Kargar S., D ra ck ley J.K. (2015). Late-gestation heat stress abatement on performance and behavior of Holstein dairy cows. J. Dairy Sci., 98: 6865-6875.

Karki U., Goodman M.S. (2010). Cattle distribution and behavior in southern-pine silvopasture versus open-pasture. Agroforestry Systems, 78: 159-168. 
L e g r a nd A.L., v o n K e y s e r 1 ing k M.A.G., We a ry D.M. (2009). Preference and usage of pasture versus free-stall housing by lactating dairy cattle. J. Dairy Sci., 92: 3651-3658.

L i u L., N i J.Q., Li Y., Erasmus M., S teven son R., Shen M. (2018). Assessment of heat stress in turkeys using animal vocalization analysis. In: 2018 ASABE Annual International Meeting (p. 1). American Society of Agricultural and Biological Engineers.

Liu S.H., Yue T.T., Ahmad M.J., Hu X.W., Zhang X.X., Deng T.X., Hu Y., He Ch., Z h o u Y., Yang L. (2020). Transcriptome analysis reveals potential regulatory genes related to heat tolerance in Holstein dairy cattle. Genes, 11: 68.

M a d e r T.L., J o h n s o n L.J., G a u g h a n J.B. (2010). A comprehensive index for assessing environmental stress in animals. J. Anim. Sci., 88: 2153-2165.

Man z o or A., M a q b o o 1 I., G a n a i e Z.A., A fza 1 I., K h a n H.M., Z a ffe B. (2019). Mitigating winter vagaries in dairy animals: A review. Int. J. Vet. Sci. Anim. Husbandry, 4: 01-05.

Marino L., A 11 e n K. (2017). The psychology of cows. Anim. Behav. Cogn., 4: 474-498.

Me en G.H., Schellekens M.A., S legers M.H.M., Le enders N.L.G., Van Erp-Van der Kooij E., Noldus L.P. (2015). Sound analysis in dairy cattle vocalisation as a potential welfare monitor. Comp. Electr. Agric., 118: 111-115.

Meng J., Shi F.H., Meng Q.X., R en L.P., Z hou Z.M., W u H., Z h a o L.P. (2015). Effects of bedding material composition in deep litter systems on bedding characteristics and growth performance of Limousin calves. Asian-Australas. J. Anim. Sci., 28: 143-150.

Min L., Li D., Tong X., Nan X., D ing D., Xu B., Wang G. (2019). Nutritional strategies for alleviating the detrimental effects of heat stress in dairy cows: a review. Int. J. Biomet., 63: $1283-1302$.

Munksgaard L., Jensen M.B., Pedersen L.J., Hansen S.W., Matthews L. (2005). Quantifying behavioural priorities - Effects of time constraints on behavior of dairy cows, Bos taurus. Appl. Anim. Behav. Sci., 92: 3-14.

National Research Council (1971). A guide to environmental research on animals. National Academy of Science, Washington.

National Research Council (2001). Nutrient Requirements of Dairy Cattle, 7th rev ed, Washington DC, National Academy Press, pp. 178-183.

Navarro G., Green L.E., Tadich N. (2013). Effect of lameness and lesion specific causes of lameness on time budgets of dairy cows at pasture and when housed. Vet. J., 197: 788-793.

Norring M., Manninen E., de Passille A.M., Rushen J., Munksgaard L., Salonie m i H. (2008). Effects of sand and straw bedding on the lying behavior, cleanliness, and hoof and hock injuries of dairy cows. J. Dairy Sci., 91: 570-576.

Olive ir a S.E., Cost a C.C., de Souza J.B. Jr., de Queiroz J.P., Maia A.S., Costa L.L. (2014). Short-wave solar radiation level willingly tolerated by lactating Holstein cows in an equatorial semi-arid environment. Trop. Anim. Health. Prod., 46: 1413-1417.

Ortiz X.A., S mith J.F., Rojano F., Choi C.Y., Bruer J., Steele T., Schuring N., Alle n J., C o 11 i e r R.J. (2015). Evaluation of conductive cooling of lactating dairy cows under controlled environmental conditions. J. Dairy Sci., 98: 1759-1771.

P e r e y r a A.V.G., M a y V.M., C a tr a c c h i a C.G., Herrero M.A., F 1 or e s M.C., M a z z in i M. (2010). Influence of water temperature and heat stress on drinking water intake in dairy cows. Chil. J. Agric. Res., 70: 328-336.

P i l a t t i J.A., Vi e i r a F.M.C. (2017). Environment, behavior and welfare aspects of dairy cows reared in compost bedded pack barns system J. Anim. Behav. Biometeorol., 5: 97-105.

Pilatt i J.A., Vie ir a F.M.C., R a n kra pe F., Vis m ar a E.S. (2019). Diurnal behaviors and herd characteristics of dairy cows housed in a compost-bedded pack barn system under hot and humid conditions. Animal, 13: 399-406.

Pint o S., Hoffmann G., A mmon Ch., A mon B., Heuwieser W., Halachmi I., Banh a z i T., A m on T. (2019). Influence of barn climate, body postures and milk yield on the respiration rate of dairy cows. Ann. Anim. Sci., 2: 469-481.

Polsky L., von Keyserlingk M.A.G. (2017). Invited review: effects of heat stress on dairy cattle welfare. J. Dairy. Sci., 100: 8645-8657.

Ratnakaran A., Sejian V., Joshe V.S., Shalini V., Madiajagan B., Krishnan G., B e en a V., Indira P.D., Varma G., B hatta R. (2017). Behavioral responses to livestock adaptation to heat stress challenges. Asian J. Anim. Sci., 11: 1-13. 
R h o a d s R.P., B a u m g a r d L., S a u g e e J.K. (2013). Metabolic priorities during heat stress with an emphasis on skeletal muscle. J. Anim. Sci., 91: 2492-2503.

Röttgen V., S chön P.C., B ecker F., Tuchscherer A., Wrenzycki C., Düpjan S., Pup p e B. (2020). Automatic recording of individual oestrus vocalisation in group-housed dairy cattle: development of a cattle call monitor. Animal, 14: 198-205.

S a i zi T., M p a y i p h l i M., I d ow u P.A. (2019). Heat tolerance level in dairy herds: a review on coping strategies to heat stress and ways of measuring heat tolerance. J. Anim. Behav. Biometeorol., 7: 39-51.

Schauberger G., Hennig-Pauka I., Zollits ch W., Hörtenhuber S.J., Baumgartner J., Niebuhr K., Piringer M., Knauder W., Anders I., Andre K., Schönh a r t M. (2020). Efficacy of adaptation measures to alleviate heat stress in confined livestock buildings in temperate climate zones. Biosyst. Eng., 200: 157-175.

S chutz K.E., R o gers A.R., P o ul ou in Y.A., Cox N.R., Tu c k e r C.B. (2010). The amount of shade influences the behavior and physiology of dairy cattle. J. Dairy Sci., 93: 125-133.

S h a n Q., M a F.T., J in Y.H, G a o D., L i H.Y., S u n P. (2020). Chromium yeast alleviates heat stress by improving antioxidant and immune function in Holstein mid-lactation dairy cows. Anim. Feed Sci. Technol., 269, doi: 10.1016/j.anifeedsci.2020.114635.

S i l v a D.C., P a s s in i R. (2018). Assessing different holding pen cooling systems through environmental variables and productivity of lactating cows. Acta Sci. Anim. Sci., 40, e36087.

S mid A.M.C., B u rgers E.E.A., Weary D.M., B okkers E.A.M., von Keyserling k M.A.G. (2019). Dairy cow preference for access to an outdoor pack in summer and winter. J. Dairy Sci., 102: 1-8.

S m i d A.M.C., W e a r y D.M., v o n K e y s e r 1 in g k M.A.G. (2020). The influence of different types of outdoor access on dairy cattle behavior. Front. Vet. Sci., 7: 257.

Srikanth K., Kw on A., L e e E., Chung H. (2017). Characterization of genes and pathways that respond to heat stress in Holstein calves through transcriptome analysis. Cell Stress Chaperon., 22: 29-42.

Ternman E., Hanninen L., Pas te 11 M., P er S.A., Ni e ls e n P. (2012). Sleep in dairy cows recorded with a non-invasive EEG technique. Appl. Anim. Behav. Sci., 140: 25-32.

Theusme C., Avendaño-Reyes L., Macías-Cruz U., Correa-Calderón A., García-Cueto R.O., Mellado M., Vargas-Villamil L., Vicente-Pérez A. (2021). Climate change vulnerability of confined livestock systems predicted using bioclimatic indexes in an arid region of México. Sci. Total Environ., 751, doi: 10.1016/j.scitotenv.2020.141779.

Tu c ke r C.B., R o ger s A.R., S c hut z K.E. (2008). Effect of solar radiation on dairy cattle behaviour, use of shade and body temperature in a pasture-based system. App. Anim. Behav. Sci., 109: $141-154$.

T u c k e r C.B., L a c y - H u 1 b e r t S.J., We b s t e r J.R. (2009). Effect of milking frequency and feeding level before and after dry off on dairy cattle behavior and udder characteristics. J. Dairy Sci., 92: 3194-3203.

Van I a e r E., M o on C., S o n c k B., Tuy t t e n s F. (2014). Importance of outdoor shelter for cattle in temperate climates. Livest. Sci., 159: 87-101.

Vasconcelos A.A., de Albuquerque C.C., de Carvalho J.F., Façanha D.A.E., Li m a F.R.G., S i lv e ir a R.M.F., F e r r e ir a J. (2020 a). Adaptive profile of dairy cows in a tropical region. Int. J. Biometerol., 64: 105-113.

Vas c once los A.M., C a rva 1 h o J.F., A 1 b u qu e rque C.C., F a ça n ha D.A.E., Ve ga W.H.O., S i lv e ir a R.M.F., F e r r e ir a J. (2020 b). Development of an animal adaptability index: Application for dairy cows. J. Therm. Biol., 89: 1-7.

Vas s e ur E., R u sh en J., H a le y D.B., d e P a s s illé A.M. (2012). Sampling cows to assess lying time for on-farm animal welfare assessment. J. Dairy Sci., 95: 4968-4977.

Vie ir a F.M.C., D en i z M., V is m a r a E.S., H e rbut P., P i l a t t i J.A., S p o n c h i a do M.Z., d e Oliveir a Puretz B. (2020). Thermoregulatory and behaviour responses of dairy heifers raised on a silvopastoral system in a subtropical climate. Ann. Anim. Sci., 20: 613-627.

Vizzotto E.F., Fischer V., Thaler Neto A., Abreu A.S., Stumpf M.T., Werncke D., S ch midt F.A., Wang D.M., Wang C., Li u H.Y., Li u J.X., F e rgu s on J.D. (2013). Effects of rumen-protected $\gamma$-aminobutyric acid on feed intake, lactation performance, and antioxidative status in early lactating dairy cows. J. Dairy Sci., 96: 3222-3227. 
We s t J.W. (2003). Effects of heat-stress on production in dairy cattle. J. Dairy Sci., 86: 2131-2144.

W e s t J.W., M u 11 i n i x B.G., B e r $\mathrm{n}$ ard J.K. (2003). Effects of hot, humid weather on milk temperature, dry matter intake and milk yield of lactating dairy cows. J. Dairy Sci., 86: 232-242.

W u W., Z h a i J., Z h ang G., N i e ls en P.V. (2012). Evaluation of methods for determining air exchange rate in a naturally ventilated dairy cattle building with large openings using computational fluid dynamics (CFD). Atmos. Environ., 63: 179-188.

Received: 16 VII 2020

Accepted: 17 XI 2020 